\title{
The Simulation of Ship Motion in Marine Environment
}

\author{
Kai Qu, Xudong Zhang, Yufeng Wang \\ Department of Aircraft Engineering, Naval Aeronautical and Astronautically University, Yantai, \\ 264000, China
}

Keywords: Ocean wave, Wave energy spectrum, Ship motion, Roll, Pitch, Heave.

\begin{abstract}
According to analyze the identity of ocean wave, the theory of wave energy spectrum was used to compute the wave elevation in some sea state. Based on establishing ship motion equations, the strip theory of the ship was used to simulate ship motion in different situation. The result showed the change of significant wave height badly influenced the amplitude of the ship motion, but it light influenced the periods of the ship motion. The change of degree of abaft the beam badly influenced the amplitude and periods of pitch, it mainly influenced periods of heave and amplitude of roll. The change of ship speed influenced the amplitude and periods of pitch, it mainly influenced periods of heave and roll.
\end{abstract}

\section{Introduction}

The work of protect the trade ocean route for Chinese navy will be more and more in the future. So Chinese navy ship will more and more cruise on the western Pacific Ocean and Indian Ocean. The wind and ocean wave of those areas are very strong. The Solid Rocket Motor (SRM) in ship will endure the loading which is caused by ship motion. How to compute the SRM's damage and evaluate its life caused by these loading have been an important research problem. (M. Xu, 2008, J.S. $\mathrm{Xu}, 2009$ )

It is the basic work to analyze the loading on SRM for damage calculation. Only exact prediction the ship motion, the life of SRM maybe evaluate which is difficult to solve. The ship strip theory is advanced (B. V. Korvin Kroukovsky, 1995, B.V. Korvin, 1957, W.Z. He, 1998), which is the available way to solve this problem. The ship strip theory is applied to simulate ship motion in different Navigation condition.

\section{Research on Wave Spectra}

Because real seas are never monochromatic, a statistical approach is needed to random seas. A common spectrum used is the Bretchneider Spectrum.

The Bretchneider Spectrum (C.L. Bretscheider, 1961) has the form:

$S_{\zeta}(\omega)=\frac{1.25}{4} \frac{\omega_{m}^{4}}{\omega^{5}} H^{2} e^{-1.25\left(\frac{\omega_{m}}{\omega}\right)^{4}}$

This spectrum requires two parameters, $H$ is the significant wave, $\omega_{m}$ and is the modal frequency. For fully developed storms, the frequency is related to the significant wave height by the equation:

$\omega_{m}=0.4 \sqrt{\frac{g}{H}}$

${ }^{g}$ Is the acceleration of gravity in the equation?

The energy density of the sea wave can be calculated by the equation:

$E=\rho g \sum_{i=1}^{\text {freg }} \frac{A_{i}^{2}}{2}=\rho g \int_{0}^{\infty} S_{\zeta}(\omega) d \omega$

$\rho$ Is the sea density, and $A_{i}$ is the wave amplitude in some frequency in the equation. It can be calculated by the equation: 
$A_{i}=\sqrt{2 S_{\zeta}\left(\omega_{i}\right) \Delta \omega}$

Adding in a random phase angle, random seas may be simulated by:

$\zeta(t)=\sum_{i=1}^{\text {freg }} A_{i} \cos \left(\omega_{i} t+\psi_{i}\right)$

An example of the record of a random sea in Sea State Five $(H=7 m)$ is shown in figure 1 . The sea state was generated using 500 discrete frequencies equally spaced from 0 to 2.5 radian/second, calculated every 0.01 seconds.

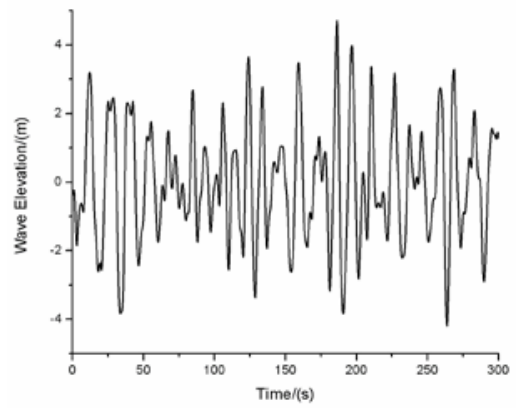

Figure 1. Fully developed Bretscheider spectrum for sea state seven

\section{Ship Motion Model}

In order to research on the ship motion, the ship coordinate need be established.

The Foundation of Ship Motion. In order to research on the ship motion in the sea wave, the two coordinates are usually applied as flowing. Both of the coordinates are right coordinates.

(1) Ship motion balance coordinate system $O-x y z$.The center of gravity position is as origin of coordinate $O$, when the ship is balance motion. $O x$ coordinate axe is parallel with horizontal plane, and point to the ship motion. $O y$ coordinate axe and $O z$ coordinate axe are apeak. $O z$ coordinate axe is apeak with horizontal plane (shown in figure 2). The coordinate directions don't change, when the ship motion's speed is constant.

(2) Ship motion coordinate system $G-x^{\prime} y^{\prime} z^{\prime}$. The center of gravity position is as origin of coordinate $G$, which is the same with ship motion balance coordinate system. $G x^{\prime}$ coordinate axe lies in the endlong middle section, point to the ship heading. Oy coordinate axe is apeak with endlong middle section, and point to larboard. $G z^{\prime}$ coordinate axe lies in the endlong middle section, point to the ship above (shown in figure 2).

(3)

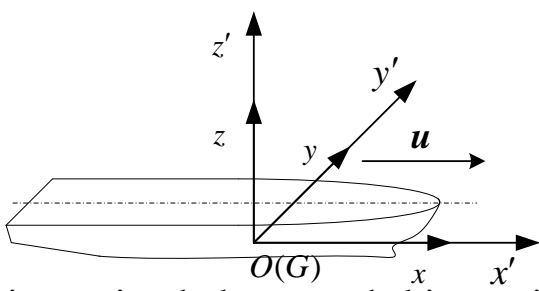

Figure 2. Ship motion balance and ship motion coordinate

Ship Motion Equations. The ship motion equations are established in the ship motion balance coordinate. The ship motion can decompound six species motion. The six motion are as flowing: surge, sway, heave, roll, pitch and yaw.

Note that $\eta_{1}$ is surge and was measured along the ship's centerline with positive forward, $\eta_{2}$ is sway and measured athwartships with positive starboard, and $\eta_{3}$ is heave with positive downwards. Looking into these axes, a positive rotation is counterclockwise. So roll $\eta_{4}$ is positive when the starboard side of the vessel is moving downward, pitch $\eta_{5}$ is positive when the bow is 
moving upwards, and yaw $\eta_{6}$ is positive when the bow is moving to starboard.

Most seakeeping analysis starts with the assumption that the motions of a ship are linear in nature. This a reasonable due to the small wave slopes experienced during most normal operating scenarios. The linearized seakeeping equations of motion for the six degrees of freedom may be written in short as (V.B. Scott, 2007):

$$
\begin{aligned}
& \sum_{k=1}^{6}\left[\left(M_{j k}+A_{j k}\right) \ddot{\eta}_{k}+B_{j k} \dot{\eta}_{k}+C_{j k} \eta_{k}\right]=F_{j} e^{i \omega t} j=1,2, \cdots 6 \\
& \mathbf{M}=\left[\begin{array}{cccccc}
m & 0 & 0 & 0 & m z_{c} & 0 \\
0 & m & 0 & -m z_{c} & 0 & 0 \\
0 & 0 & m & 0 & 0 & 0 \\
0 & -m z_{c} & 0 & I_{44} & 0 & -I_{46} \\
m z_{c} & 0 & 0 & 0 & I_{55} & 0 \\
0 & 0 & 0 & -I_{46} & 0 & I_{66}
\end{array}\right] \mathbf{A}=\left[\begin{array}{cccccc}
A_{11} & 0 & A_{13} & 0 & A_{15} & 0 \\
0 & A_{22} & 0 & A_{24} & 0 & A_{26} \\
A_{31} & 0 & A_{33} & 0 & A_{35} & 0 \\
0 & A_{42} & 0 & A_{44} & 0 & A_{46} \\
A_{51} & 0 & A_{53} & 0 & A_{55} & 0 \\
0 & A_{62} & 0 & A_{46} & 0 & A_{66}
\end{array}\right] \mathbf{B}=\left[\begin{array}{cccccc}
B_{11} & 0 & B_{13} & 0 & B_{15} & 0 \\
0 & B_{22} & 0 & B_{24} & 0 & B_{26} \\
B_{31} & 0 & B_{33} & 0 & B_{35} & 0 \\
0 & B_{42} & 0 & B_{44} & 0 & B_{46} \\
B_{51} & 0 & B_{53} & 0 & B_{55} & 0 \\
0 & B_{62} & 0 & B_{46} & 0 & B_{66}
\end{array}\right] \quad\left[\begin{array}{cccccc}
0 & 0 & 0 & 0 & 0 & 0 \\
0 & 0 & 0 & 0 & 0 & 0 \\
0 & 0 & C_{33} & 0 & C_{35} & 0 \\
0 & 0 & 0 & C_{44} & 0 & 0 \\
0 & 0 & C_{53} & 0 & C_{55} & 0 \\
0 & 0 & 0 & 0 & 0 & 0
\end{array}\right]
\end{aligned}
$$

Expanding the equations (6) with all coefficients in them shows a very interesting phenomenon. Because of the symmetrical zeroes in each matrix, the whole system divides into two sets of three coupled equations; one set consisting of surge, heave, and pitch, and the other set describing sway, roll, and yaw. This can further be simplified, as Salveson (N. Salveson, 1970) point out, by noting that the surge force and the surge response, are very small compared to the other forces and motions. The equations of motion for each fixed frequency are then:

$$
\begin{gathered}
\left(M+A_{33}\right) \ddot{\eta}_{3}+B_{33} \dot{\eta}_{3}+C_{33} \eta_{3}+A_{35} \ddot{\eta}_{5}+B_{35} \dot{\eta}_{5}+C_{35} \eta_{5}=F_{3}(t) e^{i \omega_{e} t} \\
A_{53} \ddot{\eta}_{3}+B_{33} \dot{\eta}_{3}+C_{53} \eta_{3}+\left(I_{55}+A_{55}\right) \ddot{\eta}_{5}+B_{55} \dot{\eta}_{5}+C_{55} \eta_{5}=F_{5}(t) e^{i \omega_{e} t} \\
\left(I_{44}+A_{44}\right) \ddot{\eta}_{4}+B_{33} \dot{\eta}_{4}+C_{44} \eta_{4}=F_{4}(t) e^{i \omega_{e} t}
\end{gathered}
$$

The equations (7) and (8) are the heave, pitch and roll equations in some frequency. Solving these equations can get the ship motion in the regular sea wave.

Solving Ship Motion Equations. The coefficients of the equations are lied on the ship dimension, direction and speed. The ship basic parameters are shown in table 1.

Table 1. Main parameters of some navy ship

\begin{tabular}{ccccc}
\hline tonnage & length & beam & baseline & Max \\
$\forall$ & $L$ & $D$ & $B$ & speed $U$ \\
\hline $6000 \mathrm{t}$ & $153 \mathrm{~m}$ & $14.6 \mathrm{~m}$ & $6 \mathrm{~m}$ & $30 \mathrm{knot}$ \\
\hline
\end{tabular}

According to solve the equation (8), it can be changed as transfer function:

$$
\operatorname{RAOH}\left(\omega_{e}\right)=\frac{\eta_{4}}{k A}=\frac{C_{44}}{\sqrt{\left(C_{44}-\left(I_{44}+A_{44}\right) \omega_{e}^{2}\right)^{2}+B_{44}^{2} \omega_{e}^{2}}}
$$

In the equation, $\tan (\alpha)=\frac{B_{44} \omega_{e}}{C_{44}-\left(I_{44}+A_{44}\right) \omega_{e}^{2}}, F_{4}=k A C_{44}, \omega_{e}$ is the wave encounter frequency, $\omega_{e}=\omega-U k \cos \beta, k$ is the wave number. $k=\omega^{2} / g, \omega$ is the wave frequency.

According to solve the equation (7), it can be derivated as flowing:

$$
\begin{aligned}
& \hat{\eta}_{3}=\frac{\hat{F}_{3} S-\hat{F}_{5} Q}{P S-Q R} \\
& \hat{\eta}_{5}=\frac{\hat{F}_{5} P-\hat{F}_{3} R}{P S-Q R} \\
& P=C_{33}-\omega_{e}^{2}\left(M+A_{33}\right)+i \omega B_{33}, Q=C_{35}-\omega_{e}^{2} A_{35}+i \omega B_{35}, R=C_{53}-\omega_{e}^{2} A_{53}+i \omega B_{53}, S=C_{55}-\omega_{e}^{2}\left(I_{55}+A_{55}\right)+i \omega B_{55} .
\end{aligned}
$$

According to solve the equation (10), the transfer functions of heave and pitch can be acquired. The $R A O S\left(\omega_{e}\right)$ and $R A O Z\left(\omega_{e}\right)$ can be calculated according to the equations (11) and (12):

$$
\operatorname{RAOS}\left(\omega_{e}\right)=\frac{\eta_{3}}{A}
$$




$$
\operatorname{RAOZ}\left(\omega_{e}\right)=\frac{\eta_{5}}{k A}
$$

In the equations, $\eta_{3}$ and $\eta_{5}$ separately express the real part of the $\hat{\eta}_{3}$ and $\hat{\eta}_{5}$

Solving Ship Motion. It is difficulty to solve ship motion transfer function directly, until the ship strip theory is advanced. The software of Maxsurf was applied to solve the function, which is based on ship strip theory.

Firstly the ship model was established by the software, the main parameters of some navy ship are shown in Table 1. The model are shown in Fig.3.

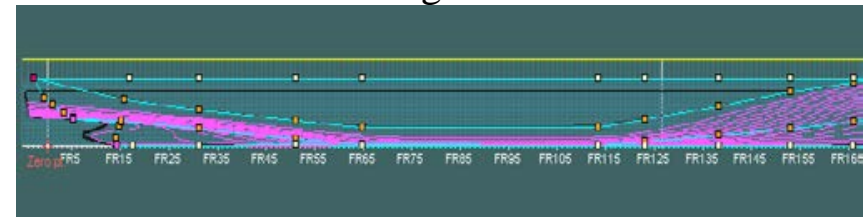

Figure 3. Side elevation of the navy ship model

After the model was established, the data of ship shape can be created by simulation. The data file can be imported to the SeaKeeper module of Maxsurf. The number of the ship strip is thirty. The ship was set to a speed of 14 knots, traveling in Sea State Five with seas 135 degrees abaft of the beam. The simulation results of the roll, pitch and heave's transfer function are shown in Fig.4.

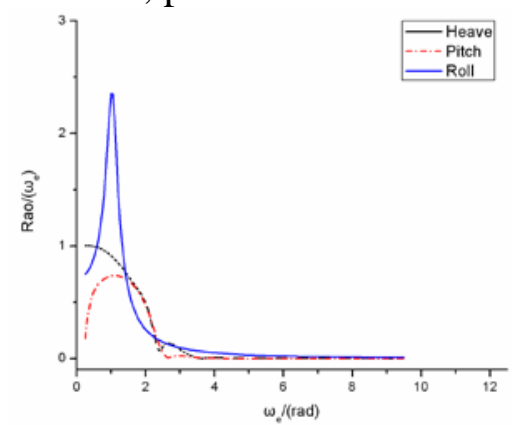

Figure 4. Amplitude-frequency response under some seakeeping scenario

\section{The Simulation of Ship Motion in Marine Environment}

Acceding to curve of the roll, pitch and heaves transfer function, the motions expressions can be calculated:

$$
\eta_{3}(t)=\sum_{i=1}^{\text {freg }} A_{i} R A O S\left(\omega_{e i}\right) \cos \left(\omega_{e i} t+\varphi_{m}\right) \quad ; \quad \eta_{4}(t)=\sum_{i=1}^{\text {freg }} A_{i} k_{i} R A O H\left(\omega_{e i}\right) \cos \left(\omega_{e i} t+\alpha_{i}\right) \quad \eta_{5}(t)=\sum_{i=1}^{\text {freg }} A_{i} k_{i} R A O Z\left(\omega_{e i}\right) \cos \left(\omega_{e i} t+\psi_{i}\right)
$$

Significant Wave Height Effect on the Ship Motion. The curve of roll, pitch and heave vs. time can be acqured in significant wave height, which are shown in Fig.5.
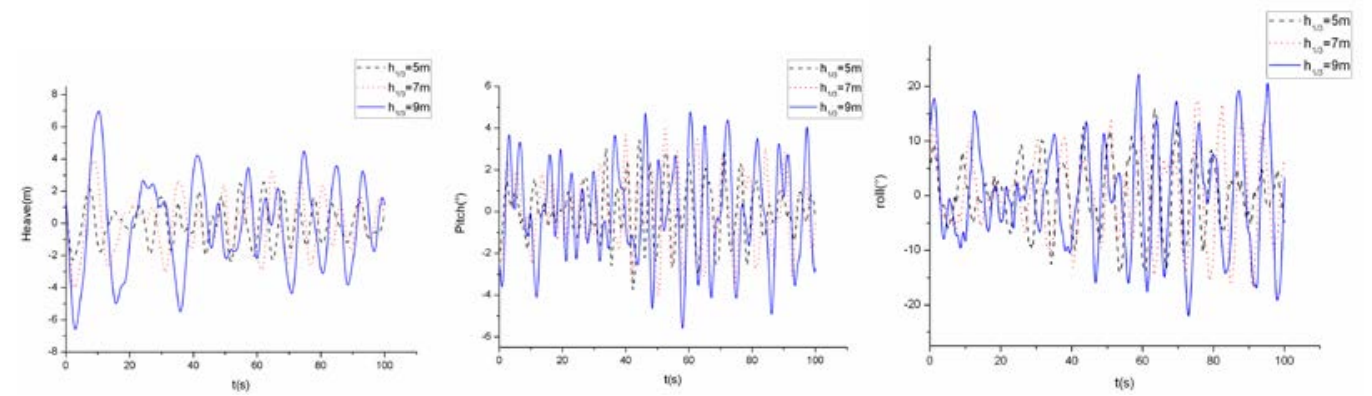

Figure 5. Heave Pitch and Roll vs. time in significant wave height

The simulation figure is shown: Change the beam degree effect on the heave's, pitch's and roll's amplitude and period.

The Shipping Degree Effect on the Ship Motion. The curve of roll, pitch and heave vs. time can be acqured in different shipping degrees, which are shown in Fig.6. 


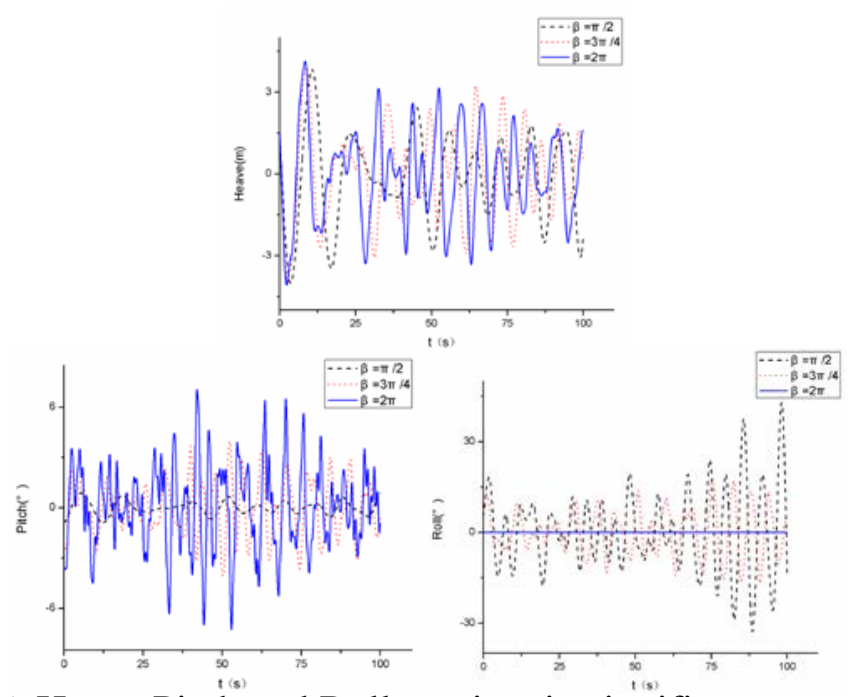

Figure 6. Heave Pitch and Roll vs. time in significant wave height

The simulation figure is shown: Change the beam degree effect on the pitch's amplitude and period, heave's period and roll's amplitude.

The Shipping Speed Effect on the Ship Motion. The curve of roll, pitch and heave vs. time can be acquired in different shipping degrees, which are shown in Fig.7.

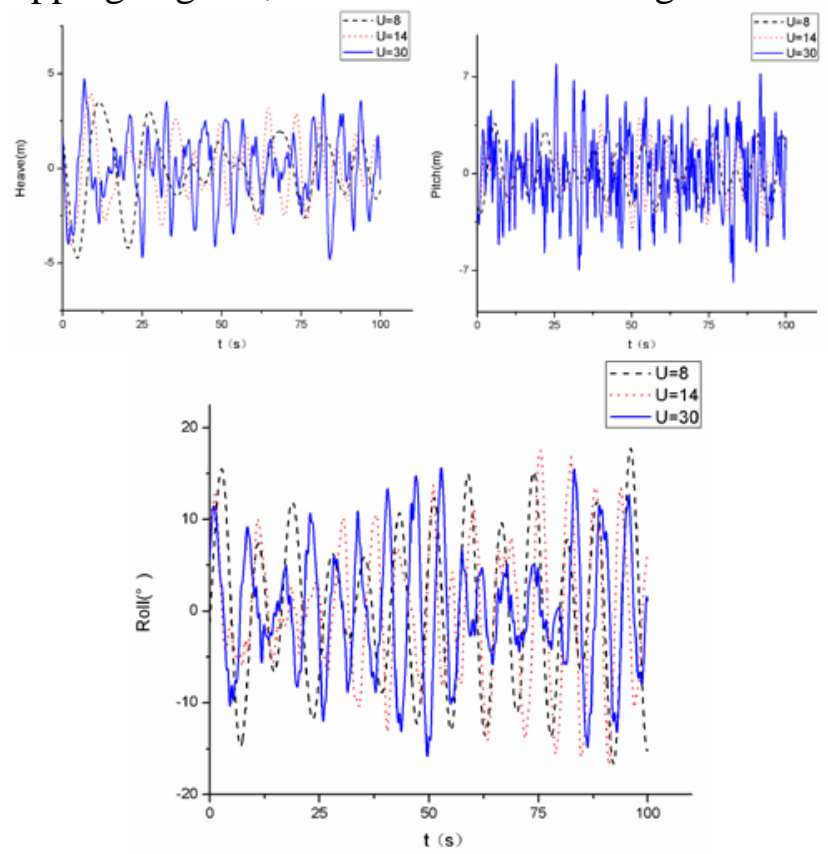

Figure 7. Heave Pitch and Roll vs. time in significant wave height

The simulation figure is shown: Increase the shipping speed can make heave and roll's period shorten. These can make pitch’s amplitude increase and period shorten.

\section{Summary}

According to the ship strip theory, the ship motion laws in different navigation conditions are researched. The conclusion can be summarized as flowing:

1) The change of significant wave height badly influenced the amplitude of the ship motion.

2) The beam degree effect different on ship three motion (heave, pitch and roll). Changing the beam degree effects on the pitch's amplitude and period, heave's period and roll's amplitude.

3) The shipping speed effect different on ship three motion (heave, pitch and roll). Increase the shipping speed can make heave and roll's period shorten. These can make pitch's amplitude increase and period shorten. 


\section{References}

1. B. V. Korvin Kroukovsky: Trans SNAME, Vol. 63 (1955) No.2, p.25.

2. B.V. Korvin Kroukovsky, W.R. Jacobs: Trans SNAME, Vol. 65 (1957) No.4, p.47.

3. C.L. Bretscheider: Proc. Conf. on Ocean Wave Spectra. (New York, America 1961), p.123.

4. J.S. Xu: Design, Life Prediction of Solid Rocket Motor Grain under the Influence of Ship Swing Load Based on the Dissipated Energy Method. (MS., Naval Aeronautical and Astronautical University, China 2009), p.20.

5. M. Xu: Design, Research on Linear Aging of Solid Rocket Motor under the Influence of Ship Swing Load (MS., Naval Aeronautical and Astronautical University, China 2008), p.10.

6. N. Salveson, E.O. Tuck, O. Faltinsen: Trans SNAME, Vol. 78 (1970) No.2, p.17.

7. V.B. Scott: Non-Linear rolling of ships in large sea waves (MS., Naval Postgraduate School, America 2007), p.22.

8. W.Z. He, Z.Q. Zhou, J. Cheng: Shipbuilding of China. , Vol. 1(1998) No.2, p.14. 